\title{
Erratum to: Non-Random Mating and Convergence Over Time for Alcohol Consumption, Smoking, and Exercise: The Nord-Trøndelag Health Study
}

\author{
Helga Ask • Kamilla Rognmo • Fartein Ask Torvik • \\ Espen Røysamb $\cdot$ Kristian Tambs
}

Published online: 5 May 2012

(C) Springer Science+Business Media, LLC 2012

\section{Erratum to: Behav Genet}

DOI 10.1007/s10519-011-9509-7

The original publication of the article includes confidence intervals for the parameter estimates that are too narrow. The authors wish to correct this and the parameter estimates with the correct $95 \%$ confidence intervals (in parentheses) are given below.

Alcohol consumption:

$$
\begin{aligned}
F 1: y= & \underset{(-0.029-0.606)}{0.289} * \exp \left(\underset{(-0.379-0.788)}{0.205} * D_{\text {neg }}\right) \\
& +\underset{(-0.0161-0.0371)}{0.0105} * \ln \left(1+\underset{(-2378-2577)}{100} * D_{\text {pos }}\right) \\
& +\underset{(-0.100-0.575)}{0.237}
\end{aligned}
$$

Smoking:

$$
\begin{aligned}
F 3: y= & \underset{(-2.079-3.096)}{0.508} * \exp \left(\underset{(-0.265-0.363)}{0.049} * D_{\text {neg }}\right) \\
& -\underset{(0.000067-0.000308)}{0.000188} *\left(D_{\text {pos }}-\underset{(-13.8-13.8)}{0.0}\right)^{2} \\
& +\underset{(-2.482-2.715)}{0.117}
\end{aligned}
$$

The online version of the original article can be found under doi:10.1007/s10519-011-9509-7.

H. Ask · K. Rognmo · F. A. Torvik · E. Røysamb - K. Tambs Division of Mental Health, Norwegian Institute of Public Health, Oslo, Norway

H. Ask $(\bowtie)$

Division of Mental Health, Norwegian Institute of Public Health, Nydalen, P.O. Box 4404, 0403 Oslo, Norway

e-mail: heas@fhi.no

E. Røysamb

Department of Psychology, University of Oslo, Oslo, Norway
Exercise:

$$
\begin{aligned}
F 3: y= & \underset{(-0.080-0.266)}{0.093} * \exp \left(\underset{(-1.091-1.639)}{0.274} * D_{\text {neg }}\right) \\
& +\underset{(0.000085-0.000322)}{0.000203} *\left(D_{\text {pos }}-\underset{(4.71-18.63)}{11.67}\right)^{2} \\
& +\underset{(0.015-0.361)}{0.188}
\end{aligned}
$$

The errors are due to an error in the weighting procedure in the nonlinear regression analysis we used. The parameter estimates remain practically unchanged. Even if some parameter estimates in the original models are no longer significant, testing a simpler model, specifying only a linear convergence before marriage/cohabitation, shows that the main conclusions remain unchanged: There are significant spouse correlations even before the spouses met, there is significant convergence during the years before marriage or cohabitation, and concordance/ discordance after marriage is moderate. Details are shown at http://www.fhi.no/artikler/?id=96795 